Article

\title{
Effect of Nut Consumption on Erectile and Sexual Function in Healthy Males: A Secondary Outcome Analysis of the FERTINUTS Randomized Controlled Trial
}

\author{
Albert Salas-Huetos ${ }^{1,2,3,+} \oplus$, Jananee Muralidharan ${ }^{1,2}$, Serena Galiè ${ }^{1,2}$, \\ Jordi Salas-Salvadó 1,2,3,4,*(D) and Mònica Bulló 1,2,3,*(D) \\ 1 Human Nutrition Unit, Biochemistry and Biotechnology Department, Faculty of Medicine and Health \\ Sciences, Universitat Rovira i Virgili (URV), 43201 Reus, Spain; albert.salas@utah.edu (A.S.-H.); \\ jananee.muralidharan@estudiants.urv.cat (J.M.); serena.galie@outlook.it (S.G.) \\ 2 Institut d'Investigació Sanitària Pere i Virgili (IISPV), 43204 Reus, Spain \\ 3 Consorcio CIBER, M.P., Physiopathology of Obesity and Nutrition (CIBERobn), Instituto de Salud Carlos \\ III (ISCIII), 28029 Madrid, Spain \\ 4 Hospital Universitari Sant Joan de Reus (HUSJR), 43204 Reus, Spain \\ * Correspondence: jordi.salas@urv.cat (J.S.-S.); monica.bullo@urv.cat (M.B.); \\ Tel.: +34-977-75-93-12 (J.S.-S. \& M.B.); Fax: +34-977-75-93-22 (J.S.-S. \& M.B.) \\ + Current affiliation: Andrology and IVF Laboratory, Division of Urology, Department of Surgery, University \\ of Utah, Salt Lake City, UT 84180, USA.
}

Received: 8 May 2019; Accepted: 17 June 2019; Published: 19 June 2019

check for updates

\begin{abstract}
Lifestyle risk factors for erectile and sexual function include smoking, excessive alcohol consumption, lack of physical activity, psychological stress, and adherence to unhealthy diets. In the present study, we evaluated the effects of mixed nuts supplementation on erectile and sexual function. Eighty-three healthy male aged 18-35 with erectile function assessment were included in this FERTINUTS study sub-analysis; a 14-week randomized, controlled, parallel feeding trial. Participants were allocated to (1) the usual Western-style diet enriched with $60 \mathrm{~g} /$ day of a mixture of nuts (nut group; $n=43$ ), or (2) the usual Western-style diet avoiding nuts (control group; $n=40$ ). At baseline and the end of the intervention, participants answered 15 questions contained in the validated International Index of Erectile Function (IIEF), and peripheral levels of nitric oxide (NO) and E-selectin were measured, as surrogated markers of erectile endothelial function. Anthropometrical characteristics, and seminogram and blood biochemical parameters did not differ between intervention groups at baseline. Compared to the control group, a significant increase in the orgasmic function $(p$-value $=0.037)$ and sexual desire $(p$-value $=0.040)$ was observed during the nut intervention. No significant differences in changes between groups were shown in peripheral concentrations of $\mathrm{NO}$ and E-selectin. Including nuts in a regular diet significantly improved auto-reported orgasmic function and sexual desire.
\end{abstract}

Keywords: nuts; RCT; erectile function; sexual desire; orgasmic function; nitric oxide; E-selectin

\section{Introduction}

National Institutes of Health (NIH) define erectile dysfunction (ED) as a persistent difficulty achieving and maintaining an erection sufficient for satisfactory sexual intercourse [1]. The prevalence of ED ranged from $2 \%$ in men younger than 40 years old, around 52\% in men aged $40-70$ years, and more than $85 \%$ in men with 80 years and older [2,3]. Although significant advances in the field were made, primary prevention research on this condition is very preliminary. Lifestyle risk factors for 
ED include smoking, excessive alcohol consumption, lack of physical activity, psychological stress, overweight or obesity, and adherence to unhealthy diets, among others [4-7].

Lifestyle factors may influence ED through the vascular and nervous system. Because adequate arterial supply is critical for erection, any disorder that impairs blood flow may be implicated in the etiology of erectile failure. However, a wide variety of psychological problems can influence the male erectile response because, in a vascular event initiated by neuronal action, it is maintained by a complex interplay between vascular, neurological events and other comorbidities [7,8]. Moreover, it is generally accepted that nitric oxide (NO) is the principal agent responsible for relaxation/erection of penile smooth muscle.

Mediterranean diet and some components of the Mediterranean diet have been inversely related to erectile and sexual dysfunction [9] but also a better endothelial function [10]. This is the case of nuts that its consumption has consistently demonstrated beneficial effects on endothelial function [11]. In fact, in a recent study, it has demonstrated that pistachio consumption improves erectile function, probably because it contains (as other types of nuts [12]) several antioxidants, and arginine, a precursor of nitric oxide (NO), a powerful compound that increases vasodilatation [13].

To demonstrate that a dietary pattern or a food group can not only modulate the erectile function, but also the sperm function increasing the chances of fertility is of great interest mainly in developed countries where male infertility seems to have fallen drastically [14], and the psychological stress seems to be more prevalent [15].

Therefore, in order to elucidate the possible role of nut consumption in the primary prevention of ED, we explored using a randomized controlled trial (RCT), the effects of nuts supplementation on erectile function determined by the International Index of Erectile Function, but also the endothelial function by measuring peripheral concentrations of $\mathrm{NO}$ and E-selectin.

\section{Materials and Methods}

\subsection{Study Design}

The study design of the FERTINUTS trial has been reported previously [16]. The trial was registered in ISRCTN registry with identifier ISRCTN12857940. Briefly, FERTINUTS was a 14-week (wk) randomized, controlled, two-interventions parallel, clinical trial conducted in healthy males who reported a Western-style diet. The trial was conducted between 2015 and 2017, and included participants who were randomly assigned (1:1) to one of the following two interventions: (1) enriching the usual Western-style diet with $60 \mathrm{~g} / \mathrm{d}$ of a mixture of raw walnuts, almonds, and hazelnuts (nut group); or (2) following the usual Western-style diet avoiding nuts (control group). The protocol was approved by the Institutional Review Board of the Hospital Universitari Sant Joan de Reus in October 2015. All the participants provided a written informed consent.

Eligible participants were healthy men aged 18-35 years old. The following exclusion criteria were applied: frequent consumption of nuts or a known history of allergy; use of plant sterol or fish oil supplements and multivitamins, vitamin E or other antioxidant supplements; history of reproductive disorders or vasectomy; current smokers; medications for chronic illness consumption; or use of illegal drugs. More detailed criteria for enrolment have been reported elsewhere [16].

The effect of the interventions on several cardiovascular risk factors and sperm parameters have been reported previously [16-18]. We report here the effect of the interventions on auto-reported erectile function parameters and the concentrations of peripheral endothelial biomarkers over 14-wk as a secondary outcome.

\subsection{Anthropometric, Dietary, Blood Parameters, and Seminogram Measurements}

Trained nurses, biologists, or dietitians directly recall all the general participants' information and conduct anthropometric measurements. The initial assessment of individuals was conducted with a 15-item dietary screener modified from Martínez-González et al., 2012 [19] to verify the presence 
of a Western-style diet adherence. Participants in the nut group received at no cost, every month, pre-weighed packs for the consumption of $60 \mathrm{~g}$ of nuts per day ( $30 \mathrm{~g}$ of walnuts, $15 \mathrm{~g}$ of almonds, and $15 \mathrm{~g}$ of hazelnuts). Participants in both groups received detailed dietary instructions in order to increase the adherence to the assigned intervention.

At baseline, participants completed a general questionnaire with a medical history, reproductive history, use of medication, and a 143-item semi-quantitative validated food frequency questionnaire (FFQ) [20] in a face-to-face interview.

During the 14-wk follow-up (with four in-site visits), weight, height, and waist circumference were recorded using a high-precision electronic scale (TANITA TBF-300, Tanita). Blood pressure was measured at rest in duplicate with a 5 minutes interval between each measurement by using a semiautomatic oscillometer (Omron HEM-705CP, Netherlands). Furthermore, all the participants completed a specific questionnaire reporting any adverse effects related or not related to the intervention, and a 3-day dietary record (3DDR) in a face-to-face interview with an expert dietitian in order to measure the compliance with the dietary intervention. Energy and nutrient intake were calculated using Spanish food composition tables [21,22]. Adherence to the intervention was also assessed by counting the empty sachets of nuts returned in each visit.

At baseline and at the end of the intervention, blood samples in $12 \mathrm{~h}$ fasting conditions and semen samples after 3 days of sexual abstinence were collected. Fasting glucose, total cholesterol, HDL cholesterol, LDL cholesterol, VLDL cholesterol, triglycerides, insulin, C-reactive protein (CRP), and folate were determined (COBAS; Roche Diagnostics Ltd, UK) in blood. Semen volume and $\mathrm{pH}$, sperm count and concentration, sperm motility, sperm viability, and sperm morphology were assessed in semen following the $2010 \mathrm{WHO}$ criteria and the Björndahl checklist [23,24].

\subsection{Erectile Function Questionnaire}

The main outcome in the present analysis was the erectile function. To evaluate the influence of nuts on erectile function, participants answered to the 15 questions contained in the validated International Index of Erectile Function (IIEF) [25] at baseline and the end of the intervention. The IIEF-15 permits to detect treatment-related changes $[25,26]$. The questionnaire of IIEF-15 addresses the relevant domains of male sexual function: erectile function (EF: 0-6 severe dysfunction, 7-12 moderate dysfunction, 13-18 mild to moderate dysfunction, 19-24 mild dysfunction, 25-30 no dysfunction), orgasmic function (OF: 0-2 severe dysfunction, 3-4 moderate dysfunction, 5-6 mild to moderate dysfunction, 7-8 mild dysfunction, 9-10 no dysfunction), sexual desire (SD: 0-2 severe dysfunction, 3-4 moderate dysfunction, 5-6 mild to moderate dysfunction, 7-8 mild dysfunction, 9-10 no dysfunction), intercourse satisfaction (IS: 0-3 severe dysfunction, 4-6 moderate dysfunction, 7-9 mild to moderate dysfunction, 10-12 mild dysfunction, 13-15 no dysfunction), and overall satisfaction (OS: 0-2 severe dysfunction, 3-4 moderate dysfunction, 5-6 mild to moderate dysfunction, 7-8 mild dysfunction, 9-10 no dysfunction).

\subsection{Surrogated Measures of Erectile Endothelial Function}

At baseline and end of the trial the peripheral concentrations of endothelial function markers, NO and E-selectin, were measured by Enzyme-Linked Immunosorbent Assay (ELISA) procedures according to the manufacturer instructions. Briefly, the NO assay kit (ThermoFisher Scientific) determines nitric oxide composition through measurement of nitrate $\left(\mathrm{NO}^{3}\right)$ and nitrite $\left(\mathrm{NO}^{2}\right)$ levels, while the E-selectin assay kit (ThermoFisher Scientific) determines the soluble E-selectin. Samples were read at $540 \mathrm{~nm}$ absorbance in the case of NO assay, and $450 \mathrm{~nm}$ absorbance in the case of E-selectin assay (TECAN, Sunrise). A polynomial curve was used as the standard. Laboratory technicians were blinded to group assignments. 


\subsection{Statistical Analyses}

The sample size for the FERTINUTS trial was calculated to detect significant differences in the viability after nut consumption based on the results of Robbins et al., 2012 [27]. However, taking into account EF changes reported in a previous similar trial [9], a total sample size of 54 (27 per arm) was estimated to provide sufficient statistical power (more than $80 \%$ ) to assess the effects of nut supplementation on erectile function parameters assuming two-sided $95 \%$ confidence interval.

Kolmogorov-Smirnov and Levene's test were used in order to check the normal distribution and homogeneity, respectively. The data are shown as means \pm standard deviation (SD) for normally distributed variables, and median \pm interquartile rank (IQR) for non-normal continuous variables. Non-parametric statistical Mann-Whitney for non-paired data and Wilcoxon tests for paired data were used to assess differences within each intervention. ANCOVA models were applied to assess differences in changes between intervention groups after adjusting for baseline values. Spearman correlation coefficients were used to calculate pair-wise correlations, and Benjamini-Hochberg false discovery rate (FDR) correction was used for multiple comparisons. Statistical analyses were conducted using per protocol approaches, including all randomized participants fulfilling all baseline and final measurements. $p$-values of $<0.05$ were considered statistically significant. Statistical analyses were carried out using the freely available R statistical computing environment v.2.14.2 (www.r-project. org) [28] and the additional package Deducer for R (http://www.deducer.org/) [29].

\section{Results}

In the FERTINUTS trial, we assessed 244 subjects for eligibility. Of these, 57 subjects declined to participate and 68 did not meet the inclusion criteria. Thus, 119 participants were included in the trial and were randomly assigned to one of the two intervention groups: 61 in the nuts group and 58 in the control group. A total 98 participants successfully completed the study, and finally, 83 participants were included in this secondary analysis (those subjects who fulfilled the International Index of Erectile Function questionnaire): 43 in the nuts supplemented group and 40 in the control group (Figure 1).

Baseline characteristics (age, weight, height, BMI, waist circumference, systolic and diastolic blood pressure, fasting glucose, serum total cholesterol, HDL cholesterol, LDL cholesterol, VLDL cholesterol, triglycerides, insulin, C-reactive protein and folate, and main sperm parameters) are detailed in Table 1. No significant differences were observed in these baseline parameters agreeing to the sequence of randomization. Participants in the two groups reported similar adherence to the Western-style diet at baseline according to the 15-item dietary screener.

Compliance with the intervention, as assessed by counting the empty sachets of nuts returned by the participants, was high ( $>95 \%$ of empty sachets returned). According to the 3DDR data, significant between-group differences in nut intake was shown through the study. This was associated with an increase in the intake total fat ( $p$-value $<0.001)$, MUFA ( $p$-value $<0.001)$, PUFA $(p$-value $<0.001)$, magnesium $(p$-value $<0.001)$, vitamin E $(p$-value $=0.014)$, omega-3 fatty acids $(p$-value $<0.001), \alpha$-Linolenic acid (ALA) $(p$-value $<0.001)$, and omega- 6 fatty acids $(p$-value $=0.016)$ in the nut-supplemented group. The intake of energy $(p$-value $=0.029)$ and fiber $(p$-value $=0.002)$ experienced a smaller decrease in the nut-supplemented group compared with the control group (Table 2). 


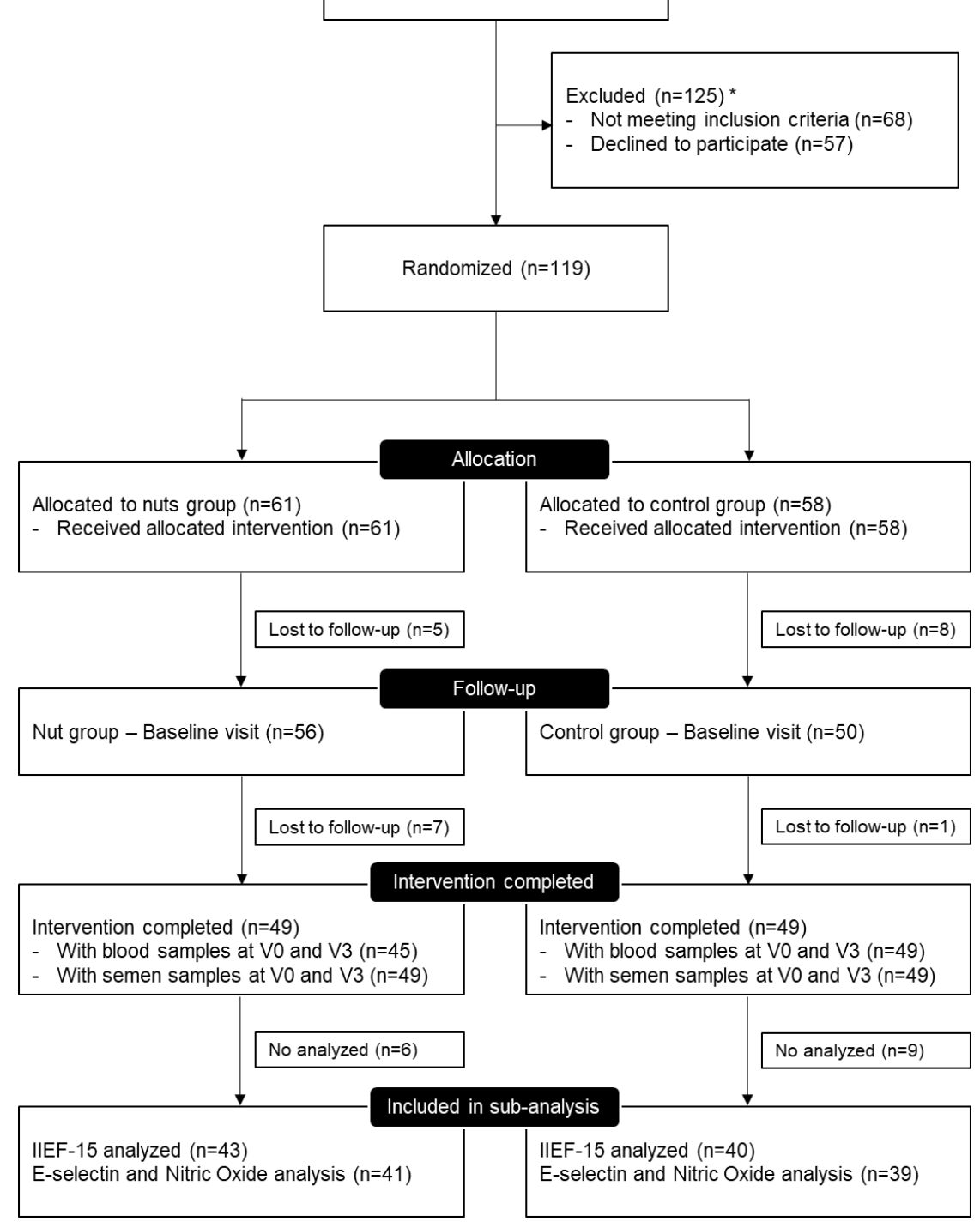

Figure 1. Flow diagram of the FERTINUTS sub-analysis. * 68 participants did not meet the inclusion criteria (ascribed to a non-Western style diet, $n=37$; smoking, $n=21$; or other minor reasons, $n=10$ ) and 57 subjects declined to participate (lack of interest, $n=34$; impossible to contact with them, $n=18$; and for non-economic compensation, $n=5$ ). 
Table 1. Baseline characteristics of the study population (general characteristics, blood, and semen parameters).

\begin{tabular}{|c|c|c|c|}
\hline Variable & Nuts Group $(n=43)$ & Control Group $(n=40)$ & $p$-Value \\
\hline \multicolumn{4}{|l|}{$\begin{array}{l}\text { General characteristics; mean } \\
\text { (SD) }\end{array}$} \\
\hline Age (years) & $24.05(4.82)$ & $25.83(4.58)$ & 0.066 \\
\hline Weight (kg) & $73.44(10.16)$ & $76.82(12.04)$ & 0.270 \\
\hline Height (cm) & $176.46(6.21)$ & $177.73(6.66)$ & 0.409 \\
\hline $\operatorname{BMI}\left(\mathrm{kg} / \mathrm{m}^{2}\right)$ & $23.53(2.59)$ & $24.33(3.64)$ & 0.379 \\
\hline Waist circumference $(\mathrm{cm})$ & $79.98(7.41)$ & $83.26(8.98)$ & 0.067 \\
\hline Systolic blood pressure (mmHg) & $129.38(11.37)$ & $126.50(11.79)$ & 0.425 \\
\hline $\begin{array}{l}\text { Diastolic blood pressure } \\
\text { (mmHg) }\end{array}$ & $73.34(7.90)$ & $70.90(8.49)$ & 0.174 \\
\hline $\begin{array}{l}\text { Score for adherence to } \\
\text { Western-style diet }\end{array}$ & $8.11(2.16)$ & $8.80(2.26)$ & 0.182 \\
\hline \multicolumn{4}{|l|}{ Blood parameters; median (IQR) } \\
\hline Fasting plasma glucose (mg/dl) & $87.0(82.0,93.5)$ & $85.5(81.5,91.0)$ & 0.384 \\
\hline Total cholesterol (mg/dl) & $167.0(149.5,188.5)$ & $173.5(150.0,196.0)$ & 0.374 \\
\hline HDL-c (mg/dl) & $58.0(49.5,66.5)$ & $55.5(50.0,67.0)$ & 0.736 \\
\hline LDL-c (mg/dl) & $87.0(74.5,105.5)$ & $98.0(77.8,119.3)$ & 0.202 \\
\hline VLDL-c (mg/dl) & $13.0(12.0,19.0)$ & $13.0(9.0,17.3)$ & 0.240 \\
\hline Triglycerides (mg/dl) & $66.0(59.0,95.5)$ & $64.0(47.0,85.0)$ & 0.258 \\
\hline $\begin{array}{l}\text { Fasting plasma insulin } \\
\qquad(\mathrm{mcUl} / \mathrm{ml})\end{array}$ & $5.40(2.60,8.60)$ & $5.20(2.75,6.80)$ & 0.654 \\
\hline C-Reactive protein (mg/dl) & $0.20(0.20,0.20)$ & $0.20(0.13,0.20)$ & 0.144 \\
\hline Folate (ng/ml) & $6.30(4.80,8.70)$ & $6.30(4.88,7.80)$ & 0.616 \\
\hline \multicolumn{4}{|l|}{$\begin{array}{c}\text { Semen characteristics; median } \\
\text { (IQR) }\end{array}$} \\
\hline $\mathrm{pH}$ & $8.0(8.0,8.5)$ & $8.0(8.0,8.5)$ & 0.940 \\
\hline Volume (mL) & $3.50(1.95,4.55)$ & $3.40(2.50,5.13)$ & 0.179 \\
\hline Total spermatozoa $\left(\times 10^{6}\right)$ & $75.20(28.10,104.50)$ & $72.05(40.90,125.50)$ & 0.497 \\
\hline $\begin{array}{l}\text { Spermatozoa concentration } \\
\qquad\left(\times 10^{6}\right)\end{array}$ & $25.20(14.50,41.80)$ & $19.80(9.70,37.95)$ & 0.402 \\
\hline Viability $(\%)$ & $78.68(70.26,82.52)$ & $80.21(73.66,85.87)$ & 0.257 \\
\hline $\begin{array}{l}\text { Total motility (progressive and } \\
\text { non-progressive motility) (\%) }\end{array}$ & $64.66(45.91,71.34)$ & $70.11(62.73,78.56)$ & 0.097 \\
\hline Progressive motility (\%) & $44.67(28.27,53.97)$ & $49.72(35.39,61.67)$ & 0.086 \\
\hline Non-progressive motility (\%) & $13.26(9.79,16.15)$ & $11.64(7.58,14.31)$ & 0.103 \\
\hline Immotile spermatozoa (\%) & $35.33(28.58,52.06)$ & $29.89(21.44,37.27)$ & 0.094 \\
\hline Normal forms (\%) & $6.33(4.91,8.17)$ & $6.27(5.23,7.57)$ & 0.935 \\
\hline Abnormal head (\%) & $52.59(43.06,66.28)$ & $55.07(41.22,67.81)$ & 0.771 \\
\hline Abnormal midpiece (\%) & $10.71(8.63,15.05)$ & $12.71(8.46,14.23)$ & 0.705 \\
\hline Abnormal principal piece (\%) & $12.94(5.44,29.66)$ & $9.46(4.53,25.27)$ & 0.529 \\
\hline Combined abnormality (\%) & $8.40(6.49,12.88)$ & $7.85(6.71,14.07)$ & 0.985 \\
\hline
\end{tabular}

Data are given as mean and standard deviation (SD) or medians and Interquartile ranges (IQRs). All the analyses were assessed by non-parametric tests (the Mann-Whitney for non-paired data) for normality distribution reasons. Equivalences: $1 \mathrm{mg} / \mathrm{dl}$ plasma glucose $=18.018 \mathrm{mmol} / \mathrm{l}, 1 \mathrm{mg} / \mathrm{dl}$ total cholesterol $=38.610 \mathrm{mmol} / \mathrm{l}$. ${ }^{\text {a }}$ The score for adherence to the Western-style diet is based on a 15-item dietary screener (a score of zero indicates minimum adherence, a score of 15 indicates maximum adherence). Abbreviations: BMI, body mass index; HDL, high-density lipoprotein; IQR, interquartile rank; LDL, low-density lipoprotein; SD, standard deviation; VLDL, very-low-density lipoprotein. 
Table 2. Nutrient intake at baseline and changes by intervention group.

\begin{tabular}{|c|c|c|c|c|c|}
\hline \multirow{2}{*}{ Variables } & \multicolumn{2}{|c|}{ Nut Group $(n=43)$} & \multicolumn{2}{|c|}{ Control Group $(n=40)$} & \multirow{2}{*}{$\frac{\text { Treatment Effec }}{p \text {-Value }}$} \\
\hline & Baseline & Changes & Baseline & Changes & \\
\hline Energy & & & & & \\
\hline $\begin{array}{l}\text { Energy intake } \\
\quad(\mathrm{kcal} / \mathrm{d})\end{array}$ & $2699.13(994.43)$ & $-145.19(31.74)$ & $2359.57(565.72)$ & $-215.22(18.18)$ & 0.029 \\
\hline Macronutrients & & & & & \\
\hline Proteins (g/d) & $112.20(39.37)$ & $-7.68(1.44)$ & $103.13(22.51)$ & $-10.45(0.34)$ & 0.065 \\
\hline $\begin{array}{l}\text { Carbohydrates } \\
\text { (g/d) }\end{array}$ & $305.24(134.16)$ & $-50.48(4.83)$ & $254.34(63.04)$ & $-11.21(0.05)$ & 0.333 \\
\hline $\begin{array}{c}\text { Simple } \\
\text { carbohydrates (g/d) }\end{array}$ & $112.70(79.80)$ & -13.47 (3.33) & $92.54(28.75)$ & $-6.31(0.06)$ & 0.696 \\
\hline $\begin{array}{c}\text { Complex } \\
\text { carbohydrates }(\mathrm{g} / \mathrm{d})\end{array}$ & $176.44(68.26)$ & $-34.36(0.84)$ & $145.29(46.70)$ & $-12.09(1.30)$ & 0.604 \\
\hline Total fat $(\mathrm{g} / \mathrm{d})$ & $106.89(40.75)$ & $12.19(0.66)$ & $97.98(30.47)$ & $-11.95(0.92)$ & $<0.001$ \\
\hline MUFA (g/d) & $42.87(18.36)$ & $5.89(0.32)$ & $37.97(15.82)$ & $-6.14(0.48)$ & $<0.001$ \\
\hline $\mathrm{SFA}(\mathrm{g} / \mathrm{d})$ & $33.33(17.87)$ & $-3.19(0.21)$ & $31.17(10.64)$ & $-3.67(0.04)$ & 0.589 \\
\hline PUFA (g/d) & $13.51(6.41)$ & $11.03(0.27)$ & $11.37(4.50)$ & $-2.60(0.23)$ & $<0.001$ \\
\hline Cholesterol (mg/d) & $426.64(253.96)$ & $-70.48(8.95)$ & 386.09 (131.85) & $-56.08(2.37)$ & 0.745 \\
\hline Fiber $(\mathrm{g} / \mathrm{d})$ & $24.69(11.21)$ & $-0.77(0.39)$ & $19.84(9.45)$ & $-2.39(0.41)$ & 0.002 \\
\hline Alcohol (g/d) & $9.43(14.01)$ & $-2.79(0.73)$ & $7.91(13.14)$ & $-2.25(0.89)$ & 0.693 \\
\hline Glycemic load & $172.69(75.43)$ & $-31.38(2.55)$ & $141.20(37.69)$ & $-5.52(0.32)$ & 0.384 \\
\hline $\begin{array}{l}\text { Glycemic index } \\
\text { Micronutrients }\end{array}$ & $56.16(4.50)$ & $-1.48(0.18)$ & $55.13(5.45)$ & $0.29(0.08)$ & 0.346 \\
\hline Sodium (mg/d) & $\begin{array}{l}3452.88 \\
(1455.36)\end{array}$ & $-407.37(26.13)$ & $3178.08(958.75)$ & $-174.95(23.37)$ & 0.743 \\
\hline Potassium (mg/d) & $\begin{array}{c}3639.91 \\
(1624.75)\end{array}$ & $-217.88(58.80)$ & $3126.17(968.16)$ & $-140.77(21.62)$ & 0.289 \\
\hline Linoleic (g/d) & $26.08(26.64)$ & $4.79(1.35)$ & $31.40(31.79)$ & $-4.66(1.24)$ & 0.311 \\
\hline Magnesium (mg/d) & 407.62 (199.96) & $32.17(7.96)$ & 329.53 (108.61) & $-16.92(0.93)$ & $<0.001$ \\
\hline Calcium (mg/d) & $987.45(514.83)$ & $-98.27(2.79)$ & 898.70 (324.53) & $-51.64(13.16)$ & 0.843 \\
\hline $\operatorname{Iron}(\mathrm{mg} / \mathrm{d})$ & $20.27(14.55)$ & $-2.04(0.60)$ & 18.35 (13.33) & $-0.11(0.47)$ & 0.864 \\
\hline Selenium (mg/d) & $222.04(162.30)$ & $-48.94(13.01)$ & $209.25(140.86)$ & $-46.06(11.51)$ & 0.563 \\
\hline $\begin{array}{c}\beta \text {-carotene } \\
\text { equivalents }(\mu \mathrm{g} / \mathrm{d})\end{array}$ & $\begin{array}{c}4711.11 \\
(5096.91)\end{array}$ & $\begin{array}{c}-1008.75 \\
(348.71)\end{array}$ & $\begin{array}{c}3913.42 \\
(4116.64)\end{array}$ & 22.34 (72.89) & 0.642 \\
\hline Retinol $(\mu \mathrm{g} / \mathrm{d})$ & $592.05(1409.67)$ & $\begin{array}{l}-230.55 \\
(169.57)\end{array}$ & $402.76(166.28)$ & 141.07 (141.29) & 0.254 \\
\hline Vitamin D $(\mu \mathrm{g} / \mathrm{d})$ & $7.37(13.90)$ & $0.55(0.31)$ & $5.05(5.65)$ & $4.50(3.67)$ & 0.606 \\
\hline Vitamin E $(\mu \mathrm{g} / \mathrm{d})$ & $13.18(5.12)$ & $6.10(1.20)$ & $15.19(18.38)$ & $-3.03(0.93)$ & 0.014 \\
\hline Vitamin $K(\mu \mathrm{g} / \mathrm{d})$ & 130.94 (163.71) & $-10.50(0.30)$ & 115.38 (111.22) & $-32.51(6.99)$ & 0.213 \\
\hline Omega-3 (g/d) & $1.72(0.89)$ & $1.53(0.02)$ & $1.68(0.73)$ & $-0.10(0.02)$ & $<0.001$ \\
\hline $\operatorname{ALA}(\mathrm{g} / \mathrm{d})$ & $1.10(0.61)$ & $1.55(0.02)$ & $1.00(0.39)$ & $-0.22(0.02)$ & $<0.001$ \\
\hline EPA (g/d) & $0.51(2.74)$ & $0.02(0.00)$ & $1.03(3.96)$ & $0.65(0.12)$ & 0.236 \\
\hline DHA (g/d) & $0.15(0.19)$ & $0.02(0.01)$ & $0.21(0.31)$ & $0.10(0.03)$ & 0.161 \\
\hline Omega-6 (g/d) & $18.03(14.80)$ & $10.27(0.08)$ & $24.64(23.36)$ & $-3.76(0.94)$ & 0.016 \\
\hline
\end{tabular}

Data are given as means and SD for baseline values, and mean and SE for changes. In bold the significant values. ANCOVA models were used to assess differences between intervention groups. Changes in variables were adjusted for baseline values of each variable. Abbreviations: ALA: $\alpha$-Linolenic acid, DHA: docosahexaenoic acid, EPA: eicosapentaenoic acid, MUFA: monounsaturated fatty acids, PUFA: polyunsaturated fatty acids, SFA: saturated fatty acids.

No significant between-group differences were observed in erectile function parameters at baseline. However, compared to the control group, a significant increase in the orgasmic function (OF; $p$-value $=0.037)$ and sexual desire (SD; $p$-value $=0.040)$ was observed in the nut-supplemented group during the intervention. No significant between-group differences in changes during the intervention were found in erectile function (EF; $p$-value $=0.192$ ), intercourse satisfaction (IS; $p$-value $=0.473$ ), and overall satisfaction $(\mathrm{OS} ; p$-value $=0.333)($ Figure 2$)$. No significant correlations were found between changes in ED parameters and changes in biochemical parameters during the intervention. 

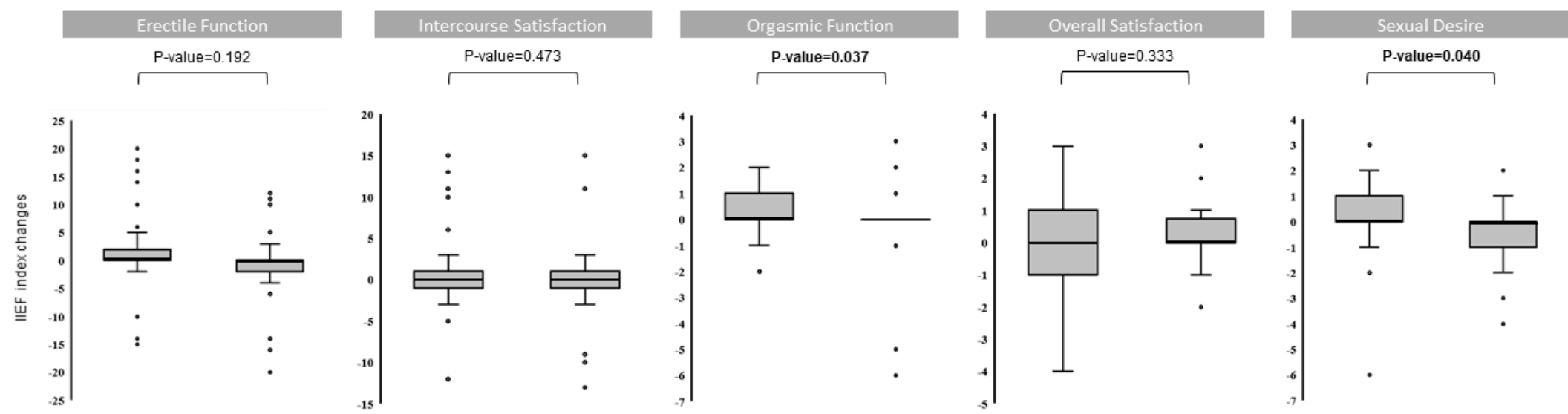

Nuts group

Control group

Nuts group

Control group

Nuts group

Control group

Nuts group

Control group

Nuts group

Control group

Figure 2. Box plot of the differences between the control group and the nut-supplemented group in the erectile function parameters (IIEF-15). ANCOVA models were used to assess differences between intervention groups. Changes were adjusted for baseline values. A horizontal line in the boxplot illustrates the median value. The upper and lower bars indicate the third and first percentiles, respectively. Outliers are plotted as individual circles. Abbreviations: IIEF: International Index of Erectile Function. 
Moreover, no significant differences in changes between intervention groups were shown in peripheral concentrations of $\mathrm{NO}(p$-value $=0.737)($ Figure $3 \mathrm{~A})$ or E-selectin $(p$-value $=0.347)($ Figure 3B $)$.

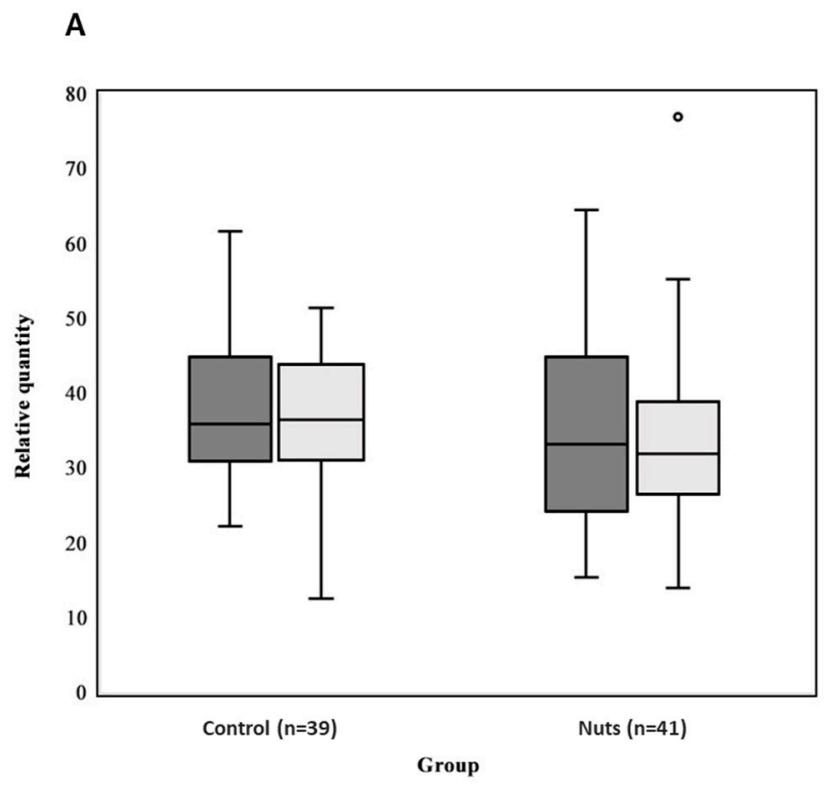

$\square$ Nitric Oxide Baseline

$\square$ Nitric Oxide Final

B

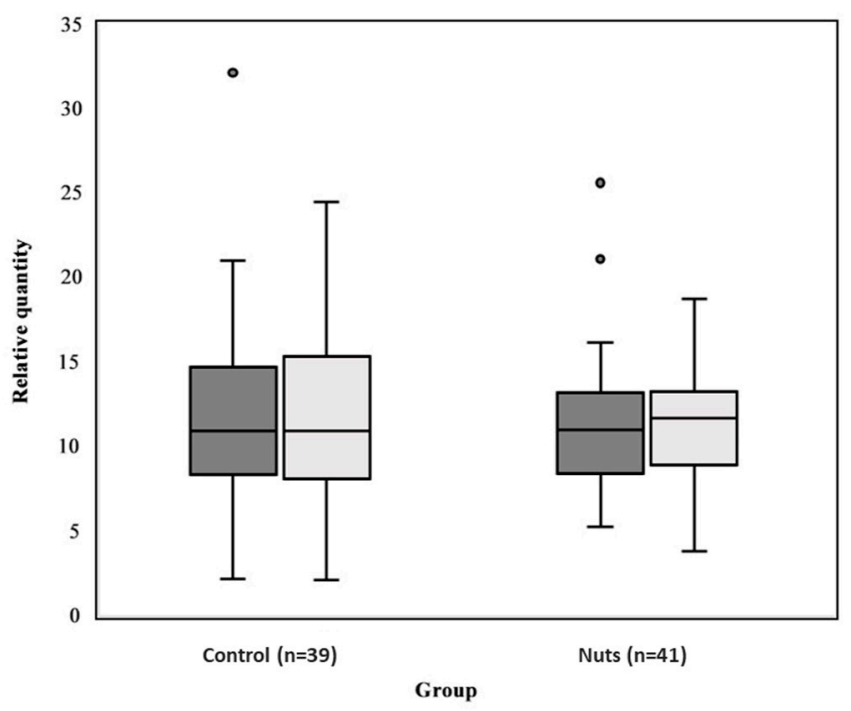

$\square$ E-selectin Baseline

$\square$ E-selectin Final

Figure 3. Box plot of the differences between the control group and the nut group in the concentrations of nitric oxide (A) and E-selectin (B) erectile function markers. ANCOVA models were used to assess differences between intervention groups. Changes were adjusted for baseline values. A horizontal line in the boxplot illustrates the median value. The upper and lower bars indicate the third and first percentiles, respectively. Outliers are plotted as individual circles. In this analysis 3 participants (2 participants in the nut group and 1 in the control group) had missing values for NO or E-selectin (see Figure 1).

\section{Discussion}

Herein we report that adding $60 \mathrm{~g} / \mathrm{d}$ of mixed raw nuts to a Western-style diet for 14-wk improved the auto-reported orgasmic function and sexual desire parameters in a group of healthy reproductive-aged participants compared with an age-matched control group. In the present study, 
none of the possible mechanisms explored ( $\mathrm{NO}$ and E-selectin as surrogated markers of endothelial function) seem to explain the beneficial effects observed on orgasmic function and sexual desire.

Interestingly, our findings in healthy young males are pretty consistent with the only previous clinical study reporting an increase of all the five IIEF-15 domains after $100 \mathrm{~g} /$ day pistachio consumption for 3 weeks [13], although this study was conducted in patients with erectile dysfunction at baseline. Therefore, our study extends the findings to a healthy population without erectile dysfunction supplemented with a mixture of nuts like hazelnuts, almonds, and walnuts.

Nuts are nutrient-dense foods with a special nutrient content, a key component of several healthy dietary patterns and recommendations, and its consumption is associated with improvements in some cardiovascular disease risk factors [30-32]. Specifically, hazelnuts, almonds and walnuts contain high amounts of vegetable protein and fat (mainly unsaturated fatty acids), are dense in antioxidants and vitamins (e.g., folic acid, niacin, tocopherols, and vitamin B6, among others) and some minerals (e.g., calcium, magnesium, phosphorous and potassium), and also rich = in dietary fiber and many other bioactive constituents (e.g., phytosterols and phenolic compounds) (Supplementary Materials Table S1 [33]).

In addition, nuts had a relatively high amount of the nonessential amino acid arginine, a precursor of NO, that is a potent vasoactive neurovascular, nonadrenergic, noncholinergic (NANC) neurotransmitter that plays an important role in erectile action through the corpora cavernosa [34]. The results from our study do not demonstrate that Arginine-NO pathway act as the unique player modulating erectile function. However, we cannot discard a lack of statistical power to demonstrate differences between intervention groups in relation to these subrogated markers of endothelial function, because the sample size of the present sub-analysis was estimated using the IIEF as the main outcome.

Another promising serum biomarker for erectile function is serum E-selectin [35]. In that case, E-selectin, because it is an endothelial dysfunction marker, seems more useful in patients diagnosed with diabetes mellitus [36]. E-selectin is a cell adhesion molecule activated by cytokines that plays an important role in inflammation. Because consuming between 60 and $90 \mathrm{~g}$ of nuts has proven effective improving inflammation [37] it could have been reasonable to detect some differences in this marker due to the nut's supplementation. Nonetheless, our study does also not confirm any effect on this endothelial marker. This lack of effect could be explained not only because of a lack of power but also because our participants were healthy and therefore without having type 2 diabetes.

Because we detected an improvement in the auto-reported orgasmic function and sexual desire parameters, maybe other mechanisms beyond those mentioned above may be implicated. It is interesting to mention that erectile (dys)function and atherogenesis share common pathways [38]. For that reason, several antioxidants (e.g., polyphenols) and vitamins, that are present in nuts, have been suggested to be effective treatments for ED and at the same time are beneficial for the cardiovascular system [38]. Previous studies reported that chronic consumption of nuts has proven effective for lowering LDL cholesterol [32] and improving glucose metabolism [39], among other cardiovascular risk factors, decreasing the incidence of major cardiovascular events [17]. Therefore, we strongly believe in the necessity to develop similar trials with participants at high cardiovascular risk and erectile dysfunction to accurately establish an effect of nut consumption on erectile function and cardiovascular risk.

Our study has several strengths. This is the largest and unique RCT to date analyzing the effect of nut supplementation on erectile and sexual function in healthy participants. Moreover, the present analysis has theoretically enough statistical power to detect effects on erectile function measured by a validated International Index of Erectile Function. Although several questionnaires have been developed to objectively evaluate EDs, the validated International Index of Erectile Function (IIEF) questionnaire is considered a valuable tool for defining the area of sexual dysfunction that may be incorporated as part of the clinical history to document the degree of dysfunction and gauge response to therapy [25]. Moreover, having detailed information on medical and reproductive history allowed us to reduce bias by excluding participants with chronic and reproductive diseases that may influence 
diet, seminogram or erectile function. The main strength of the present study is the design because RCTs represent the cornerstone of evidence-based medicine.

However, the following limitations need to be highlighted. The present study is based on a secondary outcome analysis of the FERTINUTS trial. Second, our study was conducted in apparently healthy and fertile participants limiting the extrapolation of the results to other populations, for example with erectile dysfunction, the inclusion of a group of subjects suffering from erectile dysfunction could help us to extend the results obtained. Third, reproductive hormonal (e.g., testosterone, prolactin, FSH, estradiol) values, which could affect erectile and sexual function are not reported. Finally, our study did not provide enough evidence to support the main mechanism for these improvements, however, an absence of evidence does not mean evidence of no effect [40]. Only equivalence trials are properly suited to demonstrate the equality of effects. For that reason, other RCT focused on markers of erectile endothelial function as possible mechanisms of the effect as main outcomes, are warranted in the future to increase the scientific evidence in the field.

\section{Conclusions}

In conclusion, our study suggests that compliance with a healthy diet supplemented with mixed nuts may help to improve erectile and sexual desire. Large studies are warranted in the future to confirm these results and elucidate possible mechanisms implicated on these benefits.

Supplementary Materials: The following are available online at http://www.mdpi.com/2072-6643/11/6/1372/s1, Table S1: Average nutrient composition of studied nuts (per $100 \mathrm{~g}$ ).

Author Contributions: A.S.-H. and J.S.-S. initiated the idea of the trial. A.S.-H., J.S.-S., and M.B. were involved in study concept and design. A.S.-H. was involved in study execution, acquisition of data, analyzed of data, wrote the manuscript and had primary responsibility for final content; J.M. and S.G. were involved in erectile function markers analysis. J.S.-S., and M.B. supervised the analysis and critically revised the manuscript. All authors provided substantial intellectual contributions and approved the final version of the manuscript.

Funding: This work was partially supported by the International Nut and Dried Fruit Council (INC) with the Grant No. 2015 INC Research Grant (PV15110S) and by Human Nutrition Unit funds. INC is a non-profit entity registered at the Register of Foundations of Catalonia, Spain. Nuts were supplied by Crisolar, Spain.

Acknowledgments: We thank all the FERTINUTS participants for their enthusiastic collaboration. The authors gratefully acknowledge Santiago Domínguez for nursery assistance, Rocío Moraleda for dietary assessment and some primary data collection, and Susana Benigno and Carles Munné for their help as editor assistance. Consorcio CIBER, M.P., Physiopathology of Obesity and Nutrition (CIBERobn), Instituto de Salud Carlos III (ISCIII). The Plan Nacional de Investigación Científica, Desarrollo e Innovación Tecnológica, the Instituto de Salud Carlos III - Fondo de Investigación Sanitaria (PI12/0153). The Fondo Europeo de Desarrollo Regional (FEDER).

Conflicts of Interest: J.S.-S. is a nonpaid member of the Scientific Advisory Council of the INC. M.B. has received research funds through her Institution from Pistachio Growers. No other potential conflicts of interest were reported.

\section{References}

1. NIH Consensus NIH Consensus Conference: NIH Consensus Development Panel on Impotence. JAMA 1993, 270, 83-90. [CrossRef]

2. Prins, J.; Blanker, M.H.; Bohnen, A.M.; Thomas, S.; Bosch, J. Prevalence of erectile dysfunction: A systematic review of population-based studies. Int. J. Impot. Res. 2002, 14, 422-432. [CrossRef]

3. Aytac, I.; McCkinlay, J.; Krane, R. The likely worldwide increase in erectile dysfunction between 1995 and 2025 and some possible policy consequences. BJU Int. 1999, 84, 50-56. [CrossRef]

4. Maiorino, M.; Bellastella, G.; Esposito, K. Lifestyle modifications and erectile dysfunction: What can be expected? Asian J. Androl. 2015, 17, 5-10.

5. Kirby, M. The circle of lifestyle and erectile dysfunction. Sex. Med. Rev. 2015, 3, 169-182. [CrossRef] [PubMed]

6. Hehemann, M.C.; Kashania, J.A. Can lifestyle modification affect men's erectile function? Transl. Androl. Urol. 2016, 5, 187-194. [CrossRef] 
7. Allen, M.S.; Walter, E.E. Erectile Dysfunction: An Umbrella Review of Meta-Analyses of Risk-Factors, Treatment, and Prevalence Outcomes. J. Sex. Med. 2019, 16, 531-541. [CrossRef]

8. Vlachopoulos, C.; Rokkas, K.; Ioakeimidis, N. Inflammation, metabolic syndrome, erectile dysfunction, and coronary artery disease: Common links. Eur. Urol. 2007, 52, 1590-1600. [CrossRef] [PubMed]

9. Esposito, K.; Ciotola, M.; Giugliano, F.; De Sio, M.; Giugliano, G.; D'Armiento, M.; Giugliano, D. Mediterranean diet improves erectile function in subjects with the metabolic syndrome. Int. J. Impot. Res. 2006, 18, 405-410. [CrossRef]

10. Schwingshackl, L.; Hoffmann, G. Mediterranean dietary pattern, inflammation and endothelial function: A systematic review and meta-analysis of intervention trials. Nutr. Metab. Cardiovasc. Dis. 2014, 24, 929-939. [CrossRef]

11. Neale, E.P.; Tapsell, L.C.; Guan, V.; Batterham, M.J. The effect of nut consumption on markers of inflammation and endothelial function: A systematic review and meta-analysis of randomised controlled trials. BMJ Open 2017, 7, e016863. [CrossRef] [PubMed]

12. Yu, Z.; Malik, V.S.; Keum, N.; Hu, F.B.; Giovannucci, E.L.; Stampfer, M.J.; Willett, W.C.; Fuchs, C.S.; Bao, Y. Associations between nut consumption and inflammatory biomarkers. Am. J. Clin. Nutr. 2016, 104, 722-728. [CrossRef] [PubMed]

13. Aldemir, M.; Okulu, E.; Neşelioğlu, S.; Erel, O.; Kayıgil, Ö. Pistachio diet improves erectile function parameters and serum lipid profiles in patients with erectile dysfunction. Int. J. Impot. Res. 2011, 23, 32-38. [CrossRef] [PubMed]

14. Levine, H.; Jørgensen, N.; Martino-Andrade, A.; Mendiola, J.; Weksler-Derri, D.; Mindlis, I.; Pinotti, R.; Swan, S.H. Temporal trends in sperm count: A systematic review and meta-regression analysis. Hum. Reprod. Update 2017, 23, 646-659. [CrossRef] [PubMed]

15. Ilacqua, A.; Izzo, G.; Emerenziani, G.P.; Baldari, C.; Aversa, A. Lifestyle and fertility: The influence of stress and quality of life on male fertility. Reprod. Biol. Endocrinol. 2018, 16, 115. [CrossRef] [PubMed]

16. Salas-Huetos, A.; Moraleda, R.; Giardina, S.; Anton, E.; Blanco, J.; Salas-Salvadó, J.; Bulló, M. Effect of nut consumption on semen quality and functionality in healthy men consuming a Western-style diet: A randomized controlled trial. Am. J. Clin. Nutr. 2018, 108, 953-962. [CrossRef] [PubMed]

17. Estruch, R.; Ros, E.; Salas-Salvadó, J.; Covas, M.-I.; Corella, D.; Arós, F.; Gómez-Gracia, E.; Ruiz-Gutiérrez, V.; Fiol, M.; Lapetra, J.; et al. Primary Prevention of Cardiovascular Disease with a Mediterranean Diet Supplemented with Extra-Virgin Olive Oil or Nuts. N. Engl. J. Med. 2018, 378, e34. [CrossRef] [PubMed]

18. Salas-Salvadó, J.; Díaz-López, A.; Ruiz-Canela, M.; Basora, J.; Fitó, M.; Corella, D.; Serra-Majem, L.; Warnberg, J.; Romaguera, D.; Estruch, R.; et al. Effect of a lifestyle intervention program with energy-restricted Mediterranean diet and exercise on weight loss and cardiovascular risk factors: One-year results of the PREDIMED-Plus trial. Diabetes Care 2018, 42, 777-788. [CrossRef] [PubMed]

19. Martínez-González, M.A.; García-Arellano, A.; Toledo, E.; Salas-Salvadó, J.; Buil-Cosiales, P.; Corella, D.; Covas, M.I.; Schröder, H.; Arós, F.; Gómez-Gracia, E.; et al. A 14-item mediterranean diet assessment tool and obesity indexes among high-risk subjects: The PREDIMED trial. PLoS ONE 2012, 7, e43134. [CrossRef] [PubMed]

20. Fernández-Ballart, J.D.; Piñol, J.L.; Zazpe, I.; Corella, D.; Carrasco, P.; Toledo, E.; Perez-Bauer, M.; Martínez-González, M.A.; Salas-Salvadó, J.; Martín-Moreno, J.M. Relative validity of a semi-quantitative food-frequency questionnaire in an elderly Mediterranean population of Spain. Br. J. Nutr. 2010, 103, 1808-1816. [CrossRef] [PubMed]

21. Moreiras, O.; Carvajal, A. Tablas de Composición de Alimentos (Food Composition Tables), 9th ed.; Ediciones Pirámide: Madrid, Spain, 2005.

22. Mataix Verdú, J. Tabla de Composición de Alimentos Españoles (Food Composition Tables), 4th ed.; Universidad de Granada: Granada, Spain, 2003.

23. World Health Organization. WHO Laboratory Manual for the Examination and Processing of Human Semen, 5th ed.; World Health Organization: Geneva, Switzerland, 2010.

24. Björndahl, L.; Barratt, C.L.R.; Mortimer, D.; Jouannet, P. "How to count sperm properly": Checklist for acceptability of studies based on human semen analysis. Hum. Reprod. 2016, 31, 227-232. [CrossRef] [PubMed] 
25. Rosen, R.C.; Riley, A.; Wagner, G.; Osterloh, I.H.; Kirkpatrick, J.; Mishra, A. The international index of erectile function (IIEF): A multidimensional scale for assessment of erectile dysfunction. Urology 1997, 49, 822-830. [CrossRef]

26. Rosen, R.C.; Cappelleri, J.C.; Iii, N.G. The International Index of Erectile Function (IIEF): A state-of-the-science review. Int. J. Impot. Res. 2002, 14, 226-244. [CrossRef] [PubMed]

27. Robbins, W.A.; Xun, L.; FitzGerald, L.Z.; Esguerra, S.; Henning, S.M.; Carpenter, C.L. Walnuts improve semen quality in men consuming a Western-style diet: Randomized control dietary intervention trial. Biol. Reprod. 2012, 87, 101-111. [CrossRef] [PubMed]

28. R Development Core Team. R: A Language and Environment for Statistical Computing; R Foundation for Statistical Computing: Vienna, Austria, 2013; ISBN 3-900051-07-0. Available online: http://www.R-project.org/ (accessed on 11 March 2019).

29. Fellows, I. Deducer: A data analysis GUI for R. J. Stat. Softw. 2012, 49, 1-15. [CrossRef]

30. Ros, E. Nuts and novel biomarkers of cardiovascular disease. Am. J. Clin. Nutr. 2009, 89, 1649S-1656S. [CrossRef] [PubMed]

31. Del Gobbo, L.C.; Falk, M.C.; Feldman, R.; Lewis, K.; Mozaffarian, D. Effects of tree nuts on blood lipids, apolipoproteins, and blood pressure: Systematic review, meta-analysis, and dose-response of 61 controlled intervention trials. Am. J. Clin. Nutr. 2015, 102, 1347-1356. [CrossRef] [PubMed]

32. Sabaté, J.; Oda, K.; Ros, E. Nut Consumption and Blood Lipid Levels: A Pooled Analysis of 25 Intervention Trials. Arch. Intern. Med. 2010, 170, 821-827. [CrossRef] [PubMed]

33. US Department of Agriculture, Agricultural Research Service, Nutrient Data Laboratory. USDA National Nutrient Database for Standard Reference. Current Version: April 2018. Available online: https://ndb.nal. usda.gov/ndb/search/list (accessed on 25 April 2019).

34. Lue, T. Erectile dysfunction. N. Engl. J. Med. 2000, 342, 1802-1813. [CrossRef] [PubMed]

35. Patel, D.P.; Craig, R.C., Jr.; Myers, J.B.; Brant, W.O.; Hotaling, J.M. Serum Biomarkers of Erectile Dysfunction in Diabetes Mellitus: A Systematic Review of Current Literature. Sex. Med. Rev. 2017, 5, 339-348. [CrossRef] [PubMed]

36. Araña Rosaínz, M.; Ojeda, M.O.; Acosta, J.R.; Elías-Calles, L.; González, N.; Herrera, O.T.; Álvarez, C.; Rodríguez, E.; Báez, M.; Seijas, E.; et al. Imbalanced Low-Grade Inflammation and Endothelial Activation in Patients with Type 2 Diabetes Mellitus and Erectile Dysfunction. J. Sex. Med. 2011, 8, 2017-2030. [CrossRef] [PubMed]

37. Gulati, S.; Misra, A.; Pandey, R.M. Effect of Almond Supplementation on Glycemia and Cardiovascular Risk Factors in Asian Indians in North India with Type 2 Diabetes Mellitus: A 24-Week Study. Metab. Syndr. Relat. Disord. 2017, 15, 98-105. [CrossRef] [PubMed]

38. Nehra, A.; Jackson, G.; Miner, M.; Billups, K.L.; Burnett, A.L.; Buvat, J.; Carson, C.C.; Cunningham, G.R.; Ganz, P.; Goldstein, I.; et al. The Princeton III Consensus Recommendations for the Management of Erectile Dysfunction and Cardiovascular Disease. Mayo Clin. Proc. 2012, 87, 766-778. [CrossRef] [PubMed]

39. Jenkins, D.J.A.; Kendall, C.W.C.; Banach, M.S.; Srichaikul, K.; Vidgen, E.; Mitchell, S.; Parker, T.; Nishi, S.; Bashyam, B.; De Souza, R.; et al. Nuts as a replacement for carbohydrates in the diabetic diet: A reanalysis of a randomised controlled trial. Diabetologia 2018, 61, 1734-1747. [CrossRef] [PubMed]

40. Alderson, P. Absence of evidence is not evidence of absence. BMJ 1995, 328, 476-477. [CrossRef] [PubMed]

(C) 2019 by the authors. Licensee MDPI, Basel, Switzerland. This article is an open access article distributed under the terms and conditions of the Creative Commons Attribution (CC BY) license (http://creativecommons.org/licenses/by/4.0/). 